University of Nebraska - Lincoln

DigitalCommons@University of Nebraska - Lincoln

Agronomy \& Horticulture -- Faculty Publications

Agronomy and Horticulture Department

1969

\title{
Light Interception and Radiative Exchange in Crop Stands
}

John Monteith

University of Nottingham, Loughborough, England

Follow this and additional works at: https://digitalcommons.unl.edu/agronomyfacpub

Part of the Plant Sciences Commons

Monteith, John, "Light Interception and Radiative Exchange in Crop Stands" (1969). Agronomy \& Horticulture -- Faculty Publications. 185.

https://digitalcommons.unl.edu/agronomyfacpub/185

This Article is brought to you for free and open access by the Agronomy and Horticulture Department at DigitalCommons@University of Nebraska - Lincoln. It has been accepted for inclusion in Agronomy \& Horticulture -Faculty Publications by an authorized administrator of DigitalCommons@University of Nebraska - Lincoln. 
Published in Physiological Aspects of Crop Yield: Proceedings of a symposium sponsored by the University of Nebraska, the American Society of Agronomy, and the Crop Science Society of America, and held at the University of Nebraska, Lincoln, Nebr., January 20-24, 1969. Edited by Jerry D. Eastin, F. A. Haskins, C. Y. Sullivan, C. H. M. Van Bavel, and Richard C. Dinauer (Madison, Wisconsin: American Society of Agronomy \& Crop Science Society of America, 1969). Copyright (C) 1969 American Society of Agronomy \& Crop Science Society of America. Used by permission. 


\title{
5
}

\section{Light Interception and Radiative Exchange in Crop Stands}

\author{
JOHN L. MONTEITH
}

University of Nottingham

Loughborough, England

\section{RADIATION AND CROPS}

Crops grow and use water because they intercept radiation from the sun, the sky, and the atmosphere. Diurnal changes of solar radiation dictate the diurnal course of photosynthesis and transpiration, and the vertical gradient of radiant flux in a canopy is a measure of the absorption of energy by foliage at different heights. Without exaggeration, the distribution of radiation within a plant community is the most important single element of microclimate.

Early ecological studies of radiation climate were mainly descriptive and were limited in scope by rather primitive instrumentation. A new quantitative approach to the subject was initiated by Monsi and Saeki (1953) and by Kasanaga and Monsi (1954) whose models of light distribution in plant canopies were a basis for many subsequent studies, both experimental and theoretical. About half the literature published in the last 15 years is concerned with the development of more elaborate models-an indication that it is easier to investigate light distribution at the desk than in the field! About a quarter of the literature describes new measurements, and the balance consists of review articles. Reviews have been so thorough and frequent (Saeki, 1963; Anderson, 1964; Reifsnyder and Lull, 1965; Loomis, Williams and Duncan, 1966) that my contribution to this symposium may appear premature, but I shall try to justify the exercise by being deliberately provocative. As an opening shot, crop ecologists are not concerned with the distribution of radiation per se but with rates of photosynthesis and with yield. The literature reveals a curious reluctance to test models of light penetration in crops by comparing predicted rates of dry matter accumulation with measurements in the field. We have scarcely begun to exploit models for the solution of agronomic problems.

In addition to the primary function of radiation in providing energy for photosynthesis, other less familiar aspects of radiation distribution may influence the pattern of growth and development in a field crop. As sunlightfilters through leaves, radiation in the "red" region of the spectrum (ca $0.66 \mu \mathrm{m}$ ) is strongly absorbed, but the absorption is slight in 
the "far-red" (ca $0.73 \mu \mathrm{m}$ ). In a dense crop, the relative intensity of far red to red radiation increases rapidly between the top of the canopy and the soil surface. Effects of this gradient, mediated by the phytochrome system, could determine the growth rates of tillers in cereals and grasses and the germination of weeds. The significance of spectral gradients in the field is still a matter for speculation rather than observation but the distribution of lichens on tree trunks has been related to vertical changes of spectral composition and infrared photography demonstrates these changes very vividly (McCree, 1968).

Another neglected aspect of radiation in crops is the gradient of longwave radiation on clear nights. Upper leaves lose radiation more rapidly, cool faster, and collect more dew than lower leaves. Although dew at the top of the crop will evaporate faster after sunrise if the sky stays clear, the number of hours for which leaves are wet may determine their susceptibility to attack by fungal diseases that need a film of water to germinate spores. The net flux of radiation at any level in a crop determines the energy available for the transfer of sensible and latent heat. Measurements of the net radiation gradient are fundamental to the analysis of microclimate (Cowan, 1968) and are needed to estimate how the turbulent exchange coefficient increases with height (E.R. Lemon, Chapter 6, this book).

To keep within the topic of our meeting, this review will be concerned primarily with the penetration of light in field crops in relation to photosynthesis. Salient features of radiation environment and leaf geometry will be described as an introduction to the measurement and theory of light distribution in the field.

\section{SPECIFICATION OF THE SYSTEM}

\section{A. Radiation}

Features of solar radiation relevant to crop ecology are:

1) The angle of incidence of the sun's rays, usually specified by the solar elevation $\beta$;

2) The spectral composition of the radiation. The waveband in which radiant energy is available for photosynthesis is usually defined by the limits 0.4 to $0.7 \mu \mathrm{m}$ corresponding to the blue and red ends of the visible spectrum. Photosynthetically active radiation in this waveband will be contracted to PAR;

3 ) The relative intensity of diffuse radiation from the blue sky, haze and clouds, and of direct radiation from the solar beam. If $\mathrm{D}$ is the irradiance of the diffuse component on a horizontal surface and $I$ is the direct irradiance on a surface at right angles to the sun's rays, the total irradiance on a horizontal surface is D $+I \sin \beta$.

In the absence of clouds and haze, scattered radiation is predominantly blue and decreases rapidly in strength towards the red end of the spectrum. Analysis of measurements reviewed by Robinson (1956) shows that the fraction of PAR in the spectrum of skylight decreases from about $80 \%$ when the sun is near the horizon $\left(\beta<10^{\circ}\right)$ to $60 \%$ when 


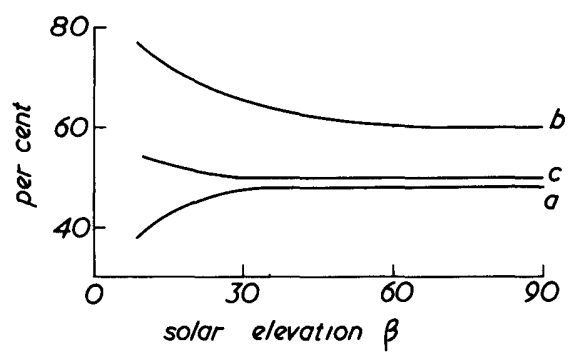

Fig. 5-1-(a) Average ratio of diffuse to total radiation as function of solar elevation from Dogniaux (1954); (b) Direct solar radiation on a horizontal surface; (c) Total (direct and diffuse) radiation on a horizontal surface. (b) and (c) were derived from measurements on a cloudless day (21 August, 1968) at Sutton Bonington and were extrapolated from $50^{\circ}$ to $90^{\circ}$ by plotting relative irradiance against air mass.

$\beta$ exceeds $60^{\circ}$ (Fig. 5-1). In contrast, the fraction of PAR in the direct beam, measured on summer days at Sutton Bonington $\left(52^{\circ} \mathrm{N} 50^{\prime} \overline{\mathrm{W}}\right)$ increasedfrom $40 \%$ when $\beta$ was less than $10^{\circ}$ to $48 \%$ when $\beta$ exceeded $30^{\circ}$.

On cloudless days, radiation at sunrise and sunset is almost entirely diffuse but the fraction of diffuse to total radiation decreases as solar elevation increases and reaches a constant minimum value when $\beta>50$. Figure 5-2 curve (a) shows the average value of this fraction determined in Belgium by Dogniaux (1954). On overcast days, all radiation is diffuse and the intensity of radiant flux increases towards the zenith. The increase can be described by an empirical formula for a "standard

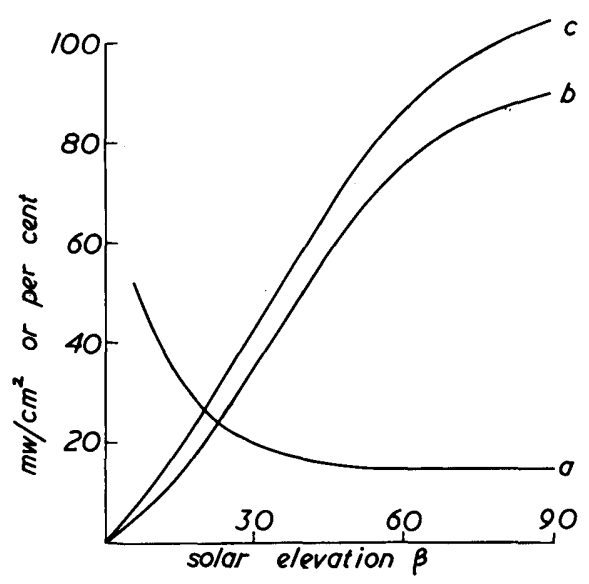

Fig. 5-2-Ratio of PAR $(0.4$ to $0.7 \mu \mathrm{m})$ to total solar radiation $(0.35$ to $3 \mu \mathrm{m})$ on a cloudless day as functions of solar elevation. (a) Direct solar radiation measured at Sutton Bonington; (b) Diffuse radiation from Robinson (1966); (c) Total (direct and diffuse) radiation by calculation. 
overcast sky" Anderson (1966) but calculations by Cowan (1968) show only trivial differences in the penetration of light into a stand from "standard" and uniformly bright skies.

Figure 5-2 curve (b) shows how the direct irradiance of a horizontal surface increased with solar elevation on a cloudless day at Sutton Bonington (21 August, 1968). Visibility was average and the atmospheric water content was about $2 \mathrm{~cm}$. Total radiation, curve (c) in Fig. 5-2, was calculated from (a) and (b). Similarly, weighting the direct and diffuse fluxes by coordinates from Fig. 5-1 (a) and (b) gives the fraction of PAR in total radiation as curve (c) in Fig. 5-1. This fraction is surprisingly constant at $50 \%$ of total radiation when the sun is more than $20^{\circ}$ above the horizon (Fig. 5-1 curve c). The lower figure of $45 \%$ often found in the literature is based on $\bar{M}$ oon's calculations for the direct beam alone and ignores the contribution from scattered radiation, rich in visible light.

The ratio of PAR to total radiation changes slightly with the amount of water vapor and dust in the atmosphere but seems to be relatively insensitive to the presence of cloud. Theoretical estimates of spectral distribution were tabulated by Avaste, Moldau and Shifrin (1962), but as the values of irradiance in Fig. 5-1 and 5-2 are difficult to abstract from the meteorological literature, they are given in Table 5-1.

\section{B. Leaves}

Most of the radiation intercepted by a field crop is absorbed by leaves, more specifically, by leaf laminae. Leaf sheaths, stems, and inflorescences also absorb radiation and are capable of photosynthesis in some species. As the relevant dimensions of these organs are seldom recorded-figures quoted by Ross and Nilson (1967a) are almost unique in the literature-discussion will be restricted to the geometry and optics of laminae.

\section{Geometry}

The area of leaf laminae within any horizontal layer of a canopy is specified by a leaf area index, $L$, the area of leaves per unit area of ground beneath them. If unit leaf layer $(L=1)$ occupies a layer of

Table 5-1-Solar irradiances $\left(\mathrm{mW} / \mathrm{cm}^{2}\right)$

\begin{tabular}{ccccccccc}
\hline $\begin{array}{c}\text { Solar } \\
\text { elevation } \\
\beta\end{array}$ & \multicolumn{3}{c}{0.3 to $4.0 \mu \mathrm{m}$} & & \multicolumn{2}{c}{0.4 to $0.7 \mu \mathrm{m}$} & \multicolumn{2}{c}{$\begin{array}{c}\text { Fraction of total } \\
\text { in waveband }\end{array}$} \\
\cline { 2 - 4 } & Direct & Diffuse & Total & & Direct & Diffuse & Total & 0.4 to $0.7 \mu \mathrm{m}$ \\
\hline 10 & 8 & 6 & 14 & & 3.1 & 4.5 & 7.6 & 54 \\
20 & 21 & 7 & 28 & & 9.5 & 4.9 & 14.4 & 52 \\
30 & 36 & 9 & 45 & & 16.6 & 5.9 & 22.5 & 50 \\
40 & 51 & 10 & 61 & & 24.5 & 6.3 & 30.8 & 50 \\
50 & 65 & 11 & 76 & & 31.3 & 6.7 & 38.0 & 50 \\
60 & 76 & 13 & 89 & & 36.4 & 7.8 & 44.2 & 50 \\
70 & 83 & 14 & 97 & & 39.8 & 8.4 & 48.2 & 50 \\
80 & 87 & 15 & 102 & & 41.7 & 8.8 & 50.5 & 50 \\
90 & 90 & 16 & 105 & & 43.0 & 9.4 & 52.4 & 50 \\
\hline
\end{tabular}


thickness $\mathrm{h} \mathrm{cm}$, the density of the foliage is $1 / \mathrm{h} \mathrm{cm}^{2}$ leaf area per $\mathrm{cm}^{3}$ of canopy volume. In crop communities, h can range from about $1 \mathrm{~cm}$ in densely sown clover to $50 \mathrm{~cm}$ or more in maize at 61,700 plants $/ \mathrm{ha}$ $(25,000$ plants/acre).

Leaves or small sections of leaves can be treated as planes making an angle $\alpha$ with the horizontal, referred to as the leaf angle. In theoretical analyses, leaves are usually assumed to be distributed at random with respect to azimuth angle, i.e., they have no preferred compass direction. In maize, however, leaves may tend to grow at right angles to the rows (Ross and Nilson, 1967b) or along the rows (R.S. Loomis and W.A. Williams, Chapter 3, this book); and in heliotropic species such as clover, leaves tend to follow the sun.

The measurement of leaf areas and angles is tedious by any method. Ross and Nilson (1967b) measured the areas of clipped sections of leaves after measuring their angles with a type of protractor, and De Wit (1965) described a method for relating leaf angle to the length of shadow case by a sphere on a white surface parallel to the leaf. The system of inclined point-quadrats developed by Warren Wilson $(1960,1963)$ relates the vertical distribution of foliage density and of mean foliage angle to the number of contacts observed between the foliage and a small spear thrust through it at a specified angle. Successful sets of measurements have been obtained in short crops with small leaves but the method is impractical for tall crops such as maize or sorghum or for foliage with large tightly packed leaves such as sugar beet (Beta vulgaris L.). Philip $(1965 \mathrm{a}, \mathrm{b})$ extended the theory of point-quadrats to derive the distribution of leaf angles and to find the minimum number of measurements needed to achieve a chosen precision. His analysis emphasises the discouragingly large number of observations required, e.g., 100 contacts to determine foliage density to $\pm 10 \%$ and at least 1,000 contacts to estimate the distribution of leaf angles.

The frequency distribution of leaf angles for a number of species was reported by De Wit (1965) and by Ross and Nilson (1967b). Using terminology introduced by De Wit, species such as clover and beans were "planophile" with a preponderance of leaves at small angles to the horizontal. Sugar beet was "plagiophile" with a fairly uniform distribution of leaf angles from 0 to $90^{\circ}$. Ryegrass was "erectophile" in early growth when more than half the leaf angles exceeded $60^{\circ}$, but as the leaves grew longer and more flaccid, they bent to form a planophile canopy with more than half the leaf angles less than $30^{\circ}$.

Nichiporovich (1961) and Ross and Nilson found (1967b) that the distribution of leaf angles in maize was close to the distribution of surface elements on a sphere. This is a special type of erectophile foliage in which the frequency of leaf angles is proportional to $\cos \alpha$. For the varieties of maize examined by De Wit and by Loomis et al. (1968), there was a significant departure from spherical foliage because of a deficit of leaf angles between $45^{\circ}$ and $90^{\circ}$. A photograph of isolated maize plants presented by Williams, Loomis, and Lepley (1965) suggests that the leaves of some varieties may be too short or too stiff to form a complete hemisphere, although individual leaves describe nearly circular arcs.

The way in which direct sunlight penetrates a crop depends on the distribution of gaps in the foliage and this aspect of canopy geometry 
is fundamental to theoretical analyses of light penetration. There are at least three methods of measuring gap frequency: from inclined pointquadrats; from hemispherical photographs taken with a camera fitted with a fish-eye lens (Evans and Coombe, 1959); from the distribution of sunflecks on a horizontal plane (Horie, 1966). Hemispherical photography has been successfully used in forests but in many crops it would be difficult to operate a camera without disturbing the foliage. Both the point-quadrat and photographic methods of determining gap frequency suffer from the serious disadvantage that they are difficult to adapt for automatic recording and demand considerable manual effort. Though unsuitable for routine work, they provide an absolute method of testing theoretical predictions in specific stands (e.g., Warren Wilson, 1965).

\section{Optics}

The transmission of radiation by leaves depends strongly on wavelength. In the region 0.4 to $0.7 \mu \mathrm{m}$ where pigments absorb most strongly, the leaves of many crop plants absorb 80 to $90 \%$ of incident radiation. Absorption is much smaller in the infrared $(0.7$ to $3 \mu \mathrm{m})$ of ten falling to 10 to $20 \%$ between 0.7 and $0.8 \mu \mathrm{m}$ (Gates et al., 1965). The proportions of radiation transmitted and reflected by crop leaves are usually similar at about 5 to $10 \%$ in the visible spectrum and 30 to $40 \%$ in the infrared. It will be assumed here that leaves transmit $7 \%$ of PAR and $25 \%$ of total solar radiation.

Because leaves absorb visible radiation preferentially, marked differences of spectral composition are observed in plant communities. Allen, Yocum, and Lemon (1964) and Singh, Peters, and Pendleton (1968), working with portable spectrophotometers, found that radiation in sunflecks was hardly modified spectrally whereas the radiation in shade was severely depleted in visible light. Averaging over sunfleck and shade areas, the attenuation of PAR is much more rapid than the attenuation of infrared or total radiation (Szeicz, Monteith, and Dos Santos, 1964; Szeicz, 1968; Allen and Brown, 1965; Tooming, 1967).

Three independent laboratory experiments are relevant to the study of light regimes in crops. First, Tageeva and Brandt (1961) measured the fraction of radiation reflected and transmitted by leaves exposed to radiation of different wavelengths and at different angles of incidence. In general, as the angle increased, reflection increased at the expense of transmission so that the fraction of radiation absorbed was almost independent of the incident angle. Second, Kriedeman, Neales, and Ashton (1964) found that when leaves were exposed to weak light, rates of photosynthesis were approximately proportional to the cosine of the angle of incidence, a result consistent with a constant absorption coefficient. In strong light, energy will still be absorbed at a rate proportional to the cosine of the angle of incidence but the rate of photosynthesis will no longer be proportional to absorbed energy. Third, Moss (1964) illuminated leaves on both sides simultaneously and showed that rates of photosynthesis were related to the gross absorption of radiant energy irrespective of its distribution on the abaxial and adaxial surfaces. Taken together, these results emphasise the need to determine 
the spatial distribution, both of radiation, and of intercepting foliage, in the canopy of a crop.

\section{MEASUREMENT OF RADIATION IN CROPS}

One of the most significant features of the radiation regime in a crop is the extreme variability of radiant fluxes both in the vertical and and in the horizontal. Many workers have taken the average of a series of spot measurements with a single photocell or solarimeter thrust randomly into the canopy at a chosen level. This method is impractical where the foliage is dense and gives misleading results if the foliage elements are pushed aside when the sensor is inserted between them. Better gradients can be obtained with a set of small sensors installed at different heights on a vertical mast. Hourly profiles of radiation may be distorted by irregularities in the distribution of foliage round the mast and by the orientation of rows with respect to solar azimuth, but a good daily average of the fractional transmission at each height can be determined by this method.

The problem of spatial integration has been attacked in two ways: by moving a single sensor backwards and forwards along a fixed path in the canopy; by exposing fixed sensors with an extended surface. Allen et al. (1964) made traverses in a dense stand of corn with an integrating photometer described by Miller (1951). Baker and Meyer (1966) mounted an Eppley solarimeter on a railway system, running at ground level through four $100-\mathrm{cm}(40$-inch) rows of cotton and completing the return journey in $18 \mathrm{~min}$. Such techniques are well suited to measurements in forests and in tall crops with widely spaced plants. In communities with small or slender plants, the use of tube solarimeters is more attractive. Thermopiles mounted within a long glass tube were first described by Isobe (1962) and were developed at Rothamsted Experimental Station (Szeicz et al., 1964; Szeicz, 1965). The standard instruments used at Rothamsted have a sensing surface $90 \mathrm{~cm}$ long and $2.5 \mathrm{~cm}$ wide and are mounted horizontally on a framework that is placed on the field as soon after germination as possible so that plants beneath them are able to grow with minimum interference to the distribution of foliage. By fitting some of the solarimeters with gelatine filters that transmit infrared radiation, the attenuation of PAR in the crop can be estimated. The main defect of tube solarimeters is the dependence of their sensitivity on solar azimuth and elevation, but by comparing the output of instruments exposed in the same direction, preferably eastwest across rows running north-south, errors are minimized. Green, Jones, and Melican (1967) modified Rothamsted solarimeters by measuring total and infrared radiation in the same tube and by exposing three tubes radially at a separation of $120^{\circ}$ to get a good average response to incident radiation.

Photochemical methods of integrating light energy tend to be unstable and temperature sensitive but for comparisons of light extinction in crops, several workers have got consistent results from the bleaching of Ozalid paper. Friend (1961) described how the paper is cut into strips and stapled into small booklets. The number of strips bleached 
after exposure to light was uniquely related to the time integral of incident energy in the waveband from 0.35 to $0.45 \mu \mathrm{m}$. With this spectral response, considerable caution is needed in the interpretation of measurements within plant communities.

The virtues and defects of many other instruments and methods were exhaustively reviewed by Anderson (1964). Gaastra (1968) examined the spectral response of different types of sensor fitted with various filters and concluded that the best estimates of attenuation in plant communities could be obtained with barrier layer photocells or with thermopiles measuring total and infrared radiation by separating the spectrum with an RG 8 filter.

When measurements of the radiant flux at different heights in a crop are supplemented by measurements of leaf area, it is possible to calculate an attenuation coefficient, related in principle to the geometry of the system. The theoretical basis of this relation will be discussed in the next section before presenting a summary of field observations.

\section{THEORETICAL PRINCIPLES}

\section{A. Random and Nonrandom Foliage}

Donald (1961) referred to "the absence in nature of the continuous profiles of horizontal foliage drawn for symposia." Nevertheless, a general theory for the transmission of radiation in crops can usefully be developed from the simplest case of an assembly of horizontal black leaves of uniform size exposed to vertical radiation. Assuming the leaf area index for the whole canopy is $\mathrm{L}$, there will be $\mathrm{L}$ similar layers containing unit leaf area, and if the arrangement of leaves within these layers is purely random, some leaves will appear to overlap their neighbors when viewed from directly overhead. For perfect randomness, the chance of $n$ leaves overlapping is given by exp-1 $n$ ! (Roach, 1968) and this is the probability of a point quadrat intercepting $n$ leaves within the layer (Duncan et al., 1967). In the limit, the probability of intercepting no leaves is $\exp -1=0.368$ : this is the fraction of radiation transmitted $\overline{b y}$ the layer. The probability of intercepting an infinite number of leaves is zero, but an inherent feature of randomness is the chance of intercepting any finite number of leaves, however large.

In real crops, leaves are not arranged at random. Their horizontal spacing is usually determined by the pattern of drilling or planting; plants are regularly spaced across rows and often along rows too. In the vertical, leaves of a single plant form a mosaic determined by phyllotaxy. When leaves from successive nodes emerge from opposite sides of the stem the chance of two or more leaves overlapping in a unit layer is significantly less than in random foliage. For example, in a stand of maize growing at 61,700 plants/ha $(25,000$ plants/acre $)$, the area per plant is $1,600 \mathrm{~cm}^{2}$ and if the average leaf area is $800 \mathrm{~cm}^{2}$, only two leaves on each plant are needed to form a unit leaf layer. As adjacent leaves on the same plant are oriented at $180^{\circ}$, overlapping will be re- 
stricted to the leaves of neighboring plants and will be slight if the leaves tend to grow across the rows. In a stand of barley with each plant occupying $10 \mathrm{~cm}^{2}$ of field area and carrying leaves with an average area of $20 \mathrm{~cm}^{2}$, unit leaf area is formed by one leaf on every second plant and overlapping will again be restricted to a much smaller range of probabilities than the random model predicts. Moreover, if there is any tendency for leaves to develop where there are gaps in the foliage as Alberda (1966) found in ryegrass, the chances of leaves overlapping within a unit layer may be negligible. In statistical terms, such an arrangement of leaves would be described as regular or very underdispersed. As an extreme contrast, crops such as lettuce (Lactuca sativa L.), drilled in widely spaced rows to allow hoeing, have leaves that are clumped or very over-dispersed and unit leaf layer contains a very large number of overlapping leaves.

Foliage in which the spatial distribution of leaves is effectively random is most likely to be found in communities where the average leaf area is much smaller than the ground area occupied by each plant. The coordinates defining the position of any leaf will then be very weakly correlated with the coordinates of most other leaves in the same layer. This condition may be satisfied in forests and in a few common crops, e.g., lucerne (Medicago sativa) and clover. Warren Wilson (1965) used inclined point-quadrats to show that the foliage of a mature stand of lucerne was effectively random but found significant departures from randomness in other communities. It is no accident that point-quadrat analysis has been applied mainly to foliage with randomly arranged leaves. The large number of contacts which the method needs accumulates most rapidly in stands with a large number of small leaves on each plant.

\section{B. Transmission in Foliage}

The theory of light transmission in nonrandom foliage was first presented by Kasanaga and Monsi (1954). They accepted the possibility that leaves within a unit layer might overlap but divided the layer into $\mathrm{n}$ sublayers within which they postulated there was no overlapping. In each such sublayer, the leaf area index is $1 / n$ and for the special case of black horizontal leaves, the sublayer transmits a fraction $(1-1 / n)$ of radiation at vertical incidence. The transmission $T(1)$ for unit leaf layer is then given by

$$
\mathrm{T}(1)=(1-1 / \mathrm{n})^{\mathrm{n}}
$$

For random foliage, $n$ must be infinite to avoid overlapping in the sublayer. The limit of $(1-1 / n)^{\mathrm{n}}$ as $1 / \mathrm{n} \longrightarrow 0$ can be obtained by writing

$$
1 / \mathrm{n} \rightarrow \underset{0}{\mathcal{L}}(1-1 / \mathrm{n})^{\mathrm{n}}=\mathcal{L} \exp [\mathrm{n} \ln (1-1 / \mathrm{n})]=\exp (-1)
$$

a result already stated.

For more general geometry, the fraction of radiation intercepted 


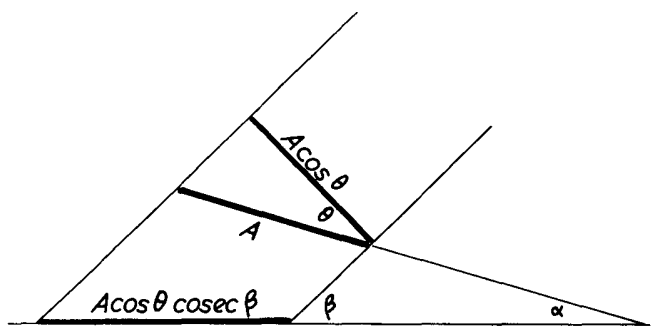

Fig. 5-3-Geometrical relations for the special case of a leaf with its normal in the plane of the sun's rays at angle $\theta: \quad \alpha$ is the leaf angle to the horizontal, and $\beta$ is the solar elevation.

by the leaves in a sublayer will be equal to the area of the shadows they cast on a horizontal surface beneath the layer. For example, if a set of leaves at an angle $\alpha$ faces towards the sun at an elevation $\beta$, the shadow area index will be $\cos \theta \operatorname{cosec} \beta$ where $\theta$ is the angle between the sun's rays and the normal to the leaf surface (Fig. 5-3). If the leaves do not face the sun but are arranged uniformly round the compass, $\cos \theta$ is replaced by $\overline{\cos \theta}$, averaging over azimuth angles from 0 to $360^{\circ}$. Then the transmission of unit leaf layer is

$$
\mathrm{T}(1)=(1-\overline{\cos \theta} \operatorname{cosec} \beta / \mathrm{n})^{\mathrm{n}} \text {. }
$$

Values of $\overline{\cos \theta}$ originally derived by Reeve (1960) are tabulated as $\left(F^{\prime} / F\right)$ by Duncan et al. (1967). When $\alpha<\beta$ only the upper surfaces of leaves are illuminated so that

$$
\overline{\cos \theta} \operatorname{cosec} \beta=\cos \alpha \sin \beta \operatorname{cosec} \beta=\cos \alpha
$$

i.e., light interception and shadow area are independent of radiation angle. When $\alpha>\beta$, either the upper or the lower surface of a leaf is illuminated depending on its azimuth and $\overline{\cos \theta} \operatorname{cosec} \beta$ assumes a more complicated form given by Reeve.

Three special cases examined by Cowan (1968) are

1) Horizontal foliage: $\cos \theta \operatorname{cosec} \beta=1$ and the expression for transmission reduces to equation (1).

2) Spherical foliage: on a plane normal to the radiation, the area of shadow cast by a sphere is half the area of the illuminated surface $\left(\pi r^{2} / 2 \pi r^{2}=1 / 2\right)$. Projected on a horizontal surface, the shadow area is $(\operatorname{cosec} \beta) / 2$ so

$$
T(1)=[1-(\operatorname{cosec} \beta) / 2 n]^{n}
$$

3) Vertical foliage: on a plane normal to the radiation the area of shadow cast by a cylinder in $2 \cos \beta / \pi$ times the illuminated area and the transmission is

$$
\mathrm{T}(1)=[1-(2 \cot \beta) / \mathrm{n} \pi]^{\mathrm{n}} .
$$




\section{Translucent Leaves}

When leaves transmit a fraction $\tau$ of the radiation falling on them in a specified waveband, the amount of light transmitted by a sub-layer will be $1-(1-\tau) \overline{\cos \theta} \operatorname{cosec} \beta / \mathrm{n}$ and the fraction of radiation transmitted by a leaf area index $L$ will be

$$
\mathrm{T}(\mathrm{L})=\{1-(1-\tau) \cos \theta \operatorname{cosec} \beta / \mathrm{n}\}^{\mathrm{nL}} .
$$

A special form of this expression was derived by Monteith (1965) who assumed that the probability of more than one interception within unit leaf layer was so small that division into sublayers was unnecessary. Then assuming $\mathrm{n}=1$ and setting $1-\mathrm{s}=\overline{\cos \theta} \operatorname{cosec} \beta$

$$
\mathrm{T}(\mathrm{L})=\{\mathrm{s}+(1-\mathrm{s}) \tau\} \mathrm{L}
$$

a binomial form that can be expanded to find the fraction of radiation reaching a given level after transmission through $0,1,2 \ldots$ leaves higher in the canopy.

Alternatively, equation (3) can be rewritten as

$$
\mathrm{T}(\mathrm{L})=\exp \left[\mathrm{L} \ln \{1-(1-\tau) \overline{\cos \theta} \operatorname{cosec} \beta / \mathrm{n}\}^{\mathrm{n}}\right]
$$

which tends for random foliage to the limit

$$
\begin{aligned}
T(L) & =\exp [-L(1-\tau) \overline{\cos \theta} \operatorname{cosec} \beta] \\
& =\exp \left(-K^{\prime} L\right)
\end{aligned}
$$

where $K^{\prime}=(1-\tau) \overline{\cos \theta} \operatorname{cosec} \beta$ is the form of extinction coefficient most quoted in the literature. To compare coefficients determined by measurements in different spectral ranges, it is convenient to work with a parameter $\mathrm{K}=\mathrm{K}^{\prime} /(1-\tau)$ depending only on the geometry of the system. In principle, the degree of randomness in foliage could be determined by comparing measurements of transmission in a canopy of specified geometry with values predicted from equations (4) and (6). In practice, $\cos \theta$ is very difficult to determine accurately and the validity of the two formulae for different crops awaits a critical test.

\section{Incident Flux}

Equations (4) and (6) describe the transmission of radiation in a canopy in terms of the relative irradiance of a horizontal surface as measured, for example, by a solarimeter or photocell. To estimate the average irradiance of inclined leaf surfaces, two factors must be taken into account. First, the average size of shadow cast by leaves is $\mathrm{K}(=\overline{\cos \theta} \operatorname{cosec} \beta)$ times the leaf area so the irradiance from the downward flux of radiation is $\mathrm{K}$ times the flux measured with an instrument facing upwards. Second, because leaves reflect radiation as well 
as transmitting, they are exposed to an upward flux in the canopy which must be added to the downward flux in order to calculate the total flux available for photosynthesis. The rigorous analytical treatment of upward and downward fluxes given by Cowan (1968) is rather cumbersome and the approximate methods used by Kuriowa (1968) and by Tooming and Ross (1964) (see Tooming, 1967) seem accurate enough in practice. In these methods, the function $\exp [-K(1-\tau)]$ describing the extinction of downward flux is replaced by exp $[-\mathrm{K}(1-\tau-\rho)]$ where $\rho$ is the reflectivity of leaves in a specific waveband. Then if the radiative flux at the top of the canopy is $I(0)$ the total upward and downward flux below leaf area $L$ is given to a good approximation by $\mathrm{I}(0) \exp [-K(1-\tau-\rho) L]$. Note that because the values of $\tau$ and $\rho$ are similar over the whole spectrum, it is unnecessary to distinguish between the radiation transmitted downward and reflected downwards, or between radiation transmitted and reflected upwards.

The radiation absorbed by leaves can be split into three components:

1) Direct radiationfrom the sun in the form of sunflecks. For random foliage, this is given by $\mathrm{K} \mathrm{I}(0)=\overline{\cos \theta} \operatorname{cosec} \beta \mathrm{I}(0)$.

2) Diffuse radiation generated within the canopy by the transmission and reflection of sunlit leaves. Below a leaf area $\mathrm{L}$, the total flux of radiation not absorbed by higher leaves is

$$
\mathrm{I}(0) \exp [-\mathrm{K}(1-\tau-\rho) \mathrm{L}]
$$

but this includes radiation penetrating the foliage without being intercepted, $\mathrm{I}(0) \exp (-\mathrm{K} \mathrm{L})$. Thus the flux of transmitted and reflected radiation is

$$
I(0) \exp (-K L)\{\exp [-K(\tau+\rho) L]-1\}
$$

The corresponding irradiance of leaves is found by multiplying this flux by a factor $K_{d}$, say, corresponding to the mean value of $\cos \theta \operatorname{cosec} \beta$ for diffuse flux. Cowan's calculations show that the diffuse flux either from a uniform or from a standard overcast sky, penetrates spherical foliage like a beam at $45^{\circ}$ giving an extinction coefficient

$$
\mathrm{K}_{\mathrm{d}}=\overline{\cos \theta} \operatorname{cosec} 45^{\circ}=0.7
$$

but for increasingly planophile foliage, $\mathrm{K}_{\mathrm{d}}$ will approach unity. Hanau (in Duncan et al., 1967) derives equations for the diffuse flux absorbed by leaves at a fixed angle.

3) Diffuse radiation from the blue sky and clouds. At the top of the canopy, the diffuse flux is assumed to be isotropic, giving an irradiance D. Then at any level specified by $L$, the total upward and downward flux of diffuse radiation will be approximately

$$
D \exp \left[-K_{d}(1-\tau-\rho) L\right]
$$

and the corresponding irradiance will be $\mathrm{K}_{\mathrm{d}}$ times this flux as in component 2 . 
The total irradiance of sunlit leaves can now be found by adding components 1,2 , and 3 and the irradiance of shaded leaves is the sum of components 2 and 3. Tooming (1967) gives approximations valid for clear and overcast skies.

For nonrandom foliage with $n=1$, a much simpler treatment is possible. In the first place, differences in the attenuation of direct and diffuse flux are not distinguished and a single factor (1 - s) describes the fraction of both types of radiation intercepted by unit leaf layer. The irradiance of leaves is therefore $(1-s)$ times the horizontal irradiance at the same level. If the total flux at the top of the canopy is $Q(=D+I \sin \beta)$, the irradiance of leaves from the downward flux will be

$$
(1-s) \mathbf{Q}\{\mathrm{s}+(1-\mathrm{s}) \tau\}^{\mathrm{L}} \text {. }
$$

The irradiance from downward and upward fluxes together is

$$
(1-s) Q\{s+(1-s)(\tau+\rho)\}^{\mathrm{L}} \text {. }
$$

It has not yet been shown whether the lack of rigor in deriving these expressions leads to significant error in subsequent calculations of photosynthesis rate.

\section{E. Sunlit Area}

To calculate the contribution to photosynthesis of sunlit and shaded leaves, it is necessary to estimate their respective areas at each height in the canopy. For random foliage, the fractional area of sunlit leaves beneath a layer with leaf area index $\mathrm{L}$ is simply $\mathrm{e}^{-\mathrm{KL}}$ and the area of all sunlit leaves in a canopy with total index $\mathrm{L}$ is given by the integral

$$
\int_{\mathrm{O}}^{\mathrm{L}} \exp -\mathrm{KL}=[1-(\exp -\mathrm{KL}) / \mathrm{K}]
$$

tending to $1 / \mathrm{K}$ at large values of $\mathrm{L}$.

In terms of the nonrandom model $(n=1)$ the area of foliage receiving radiation from sun and sky is 1 in the first leaf layer, $s$ in the second, $s^{2}$ in the third, etc. (Monteith, 1965). The total area of foliage exposed to sun and sky is

$$
{\underset{0}{\Sigma}}_{0}^{L} s^{n}=\left(1-s^{n}\right) /(1-s) .
$$

A similar function of $s$ was derived for the area of leaves receiving light transmitted through one higher leaf but this is an unrealistic distinction. It might be better to treat the radiation scattered by foliage as uniformly distributed over the surfaces of leaves in neighboring layers including leaves that are exposed to direct sunlight. 
Equation (7) predicts that sunlit area will depend on solar elevation because $K$ is given by $\overline{\cos \theta} \operatorname{cosec} \beta$. In contrast, when $\mathrm{s}$ is assigned the constant value $(1-\cos \alpha)$ the sunlit area $\left(1-s^{n}\right) /(1-s)$ is constant during the day. The difference between the two predicted areas is large when $\alpha$ is taken as $66^{\circ}$ to give $s=0.6$ as observed in barley (Warren Wilson, 1965). However, measurements of transmission in several crops reveal little diurnal change of $s$ and recent measurements in maize (Horie, 1966) showed that the area of sunflecks was relatively constant during the day.

\section{F. Longwave Radiation}

The exchange of longwave radiation in crops depends on the transmission of diffuse fluxes upwards and downwards. In the simplest case when the soil and foliage are at the same radiative temperature $\mathrm{T}^{\circ} \mathrm{K}$, the emission of flux per unit area of foliage will be $\sigma \mathrm{T}^{4}$ where $\sigma$ is Stefan's constant. The downward flux of radiation from the atmosphere can be written $\epsilon \sigma \mathrm{T}^{4}$ where $\epsilon$ is an effective emissivity depending on water vapor content and on cloudiness. (In practice, $\epsilon$ will range from from about 0.7 when the air is very dry and the sky is cloudless to 1.0 when the sky is heavily overcast.) The intensity of longwave radiation increases from the zenith to the horizon, so the extinction coefficient for atmospheric radiation will not be exactly the same as the coefficient for longwave radiation emitted by foliage. In practice, the difference will be trivial and it is safe to assume that the extinction coefficient appropriate for longwave fluxes, irrespective of their origin, is the same as the coefficient $\mathrm{Kd}$ for diffuse shortwave radiation. Then at any level in the crop specified by a leaf area index L below the top of the canopy, the downward flux of longwave radiation will be $\epsilon \sigma \mathrm{T}^{4} \exp$ $\left(-K_{d} L\right)$ from the atmosphere and $\sigma T^{4}\left[1-\exp \left(-K_{d} L\right]\right.$ from higher leaves. The upward flux will be $\sigma \mathrm{T}^{4}$ when the foliage and soil are isothermal so the net longwave flux will be $(1-\epsilon) \sigma T^{4} \exp \left(-K_{d} L\right)$.

Measurements to be reviewed in the next section suggest that profiles of shortwave, longwave, and net radiation are sometimes very similar in shape. This similarity would be expected in planophile foliage with $\alpha<\beta$ for most leaves so that $\mathrm{K}_{\mathrm{d}} \approx \mathrm{K} \approx \overline{\cos \alpha}$. On the other hand, when the temperature of the foliage departs from the soil temperature by more than a few degrees, profiles may be similar in shape near the top of the canopy but may diverge near the soil surface. This behavior can be inferred from measurements reported in bulrush millet by Begg et al. (1964); and in maize by Tanner, Peterson, and Love (1960), and by Denmead, Fritschen, and Shaw (1962). A simple analytical treatment of nonisothermal foliage was given by Saito (1964).

\section{MEASUREMENTS}

The literature contains numerous measurements of radiation in crop communities but they are difficult to relate because so few workers have used the same instruments in the same way and reported their re- 


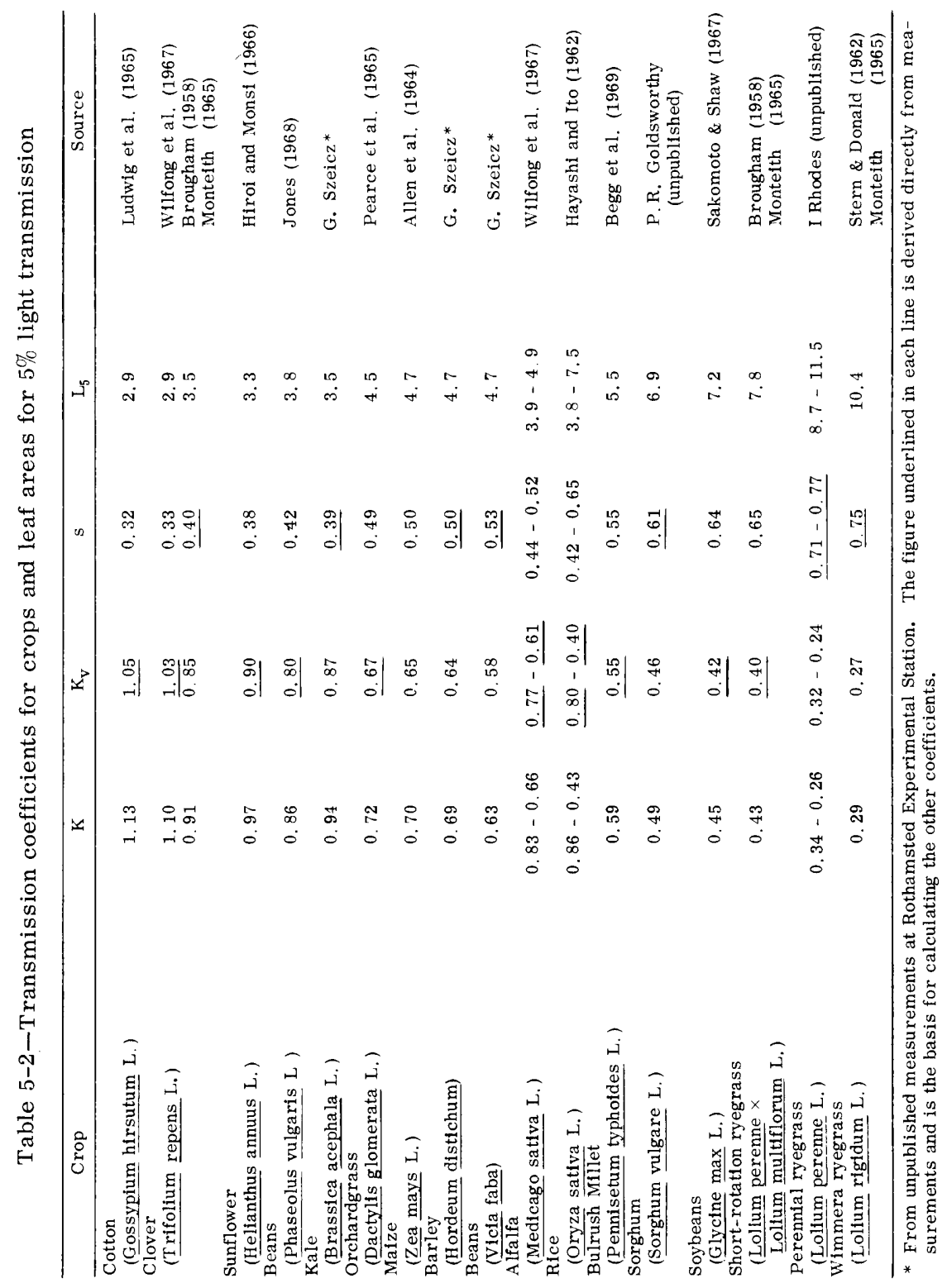


sults in the same form. For a consistent comparison, measurements from different sources were summarized by three related coefficients:

1) The extinction coefficient for visible radiation $\mathrm{KV}$ derived from measurements of direct and diffuse flux with a photocell;

2) The general extinction coefficient $\mathrm{K}=\mathrm{K}_{\mathrm{V}}^{\prime} /(1-\tau)$ with $\tau$ assumed to be 0.07 for visible radiation;

3) The coefficients derivedfrom equation (4) with $\tau=0.25$ for total solar radiation or from $\mathrm{s}=\mathrm{e}^{-\mathrm{K}}$.

A parameter of more direct agronomic interest is the leaf area index at which the amount of light transmitted by a canopy becomes trivial. By convention, the limit of transmission is taken as $5 \%$ and the corresponding leaf area $L_{5}$ is given by

$$
0.05=\exp \left(-\mathrm{K}_{\mathrm{V}}^{\prime} \mathrm{L}_{\mathbf{5}}\right) .
$$

Taking logarithms, $\mathrm{L}_{5}=3 / \mathrm{K}_{\mathrm{V}}^{\prime}$.

Table 5-2 presents estimates of extinction coefficients and of $\mathrm{L}_{5}$ for 16 species. They are arranged in order of decreasing $\mathrm{K}$ and increasing $\mathrm{s}$,i.e., starting with planophile canopies and moving towards erectophile canopies. Some of the measurements on which the table was based will be discussed in more detail, following the same sequence.

\section{Cotton}

In a growth room experiment, the intensity of light measured with an EEL photometer was a strictly logarithmic function of the cumulative leaf area index implying no change of extinction coefficient with depth in the community (Ludwig, Saeki, and Evans, 1965). In a field crop with 101-cm (40-inch) rows, different diurnal variations of light interception and photosynthesis rate were observed in rows running east-west and north-south (Baker and Meyer, 1966). Daily rates of photosynthesis were indistinguishable, however.

\section{Clover}

Brougham (1958) found a strong diurnal variation of the fraction of light transmitted by a stand of white clover, e.g., from $1.6 \%$ at $\beta=230$ to $13 \%$ at $\beta=71^{\circ}$. This result is inconsistent with the planophile nature of the foliage and with Brougham's comment that the leaves exhibited phototropism.

\section{Kale}

From measurements with tube solarimeters, the transmission of total solar radiation decreased logarithmically with the leaf area index as Fig. 5-4 shows but the parameter $\mathrm{s}$ was effectively constant within \pm 4 hours of solar noon and was slightly larger on clear than on overcast days. 


\section{Maize}

There are more published measurements of radiation in maize than in any other species. In mature canopies, the diurnal change of $\mathrm{K}_{\mathrm{V}}$ was small with \pm 4 hours of noon (Allen et al., 1964; Allen and Brown, 1965). Loomis et al. (1968) found a preponderance of leaves at $\alpha<45^{\circ}$ when the population density was 48,000 plants/ha or less, but more vertical leaves $\left(\alpha>45^{\circ}\right)$ predominated at 125,000 plants $/$ ha. This behavior is consistent with the large values of $\mathrm{L}_{5}(7.8$ to 9.3$)$ reported in earlier work with dense stands (Williams et al., 1965) and with the observation by Allen and Brown (1965) that KV may be anomalously small in the upper part of a maize canopy where young leaves tend to be clustered around the stalks. Loomis et al. (1968) were unable to relate $\mathrm{KV}$ closely to the distribution of leaf angles, but for the species of maize studied by Nichiporovich (1961) and by Ross and Nilson (1967b), the distribution was almost spherical implying $K_{V}=1 / 2 \sin \beta$ in good agreement with their measurements of transmission. Duncan, Williams, and Loomis (1967) drew attention to the significant amount of light absorbed by tassels and calculated that the shadow cast on foliage would reduce leaf photosynthesis by about $10 \%$ at a population of 50,000 plants $/$ ha.

\section{Barley}

From unpublished figures supplied by P.V. Biscoe, the percentage transmission did not change systematically within \pm 5 hours of noon (Fig. 5-5). In a stand growing to $90 \mathrm{~cm}$, the transmission of total solar radiation and of net radiation were almost identical at a height of $10 \mathrm{~cm}$.

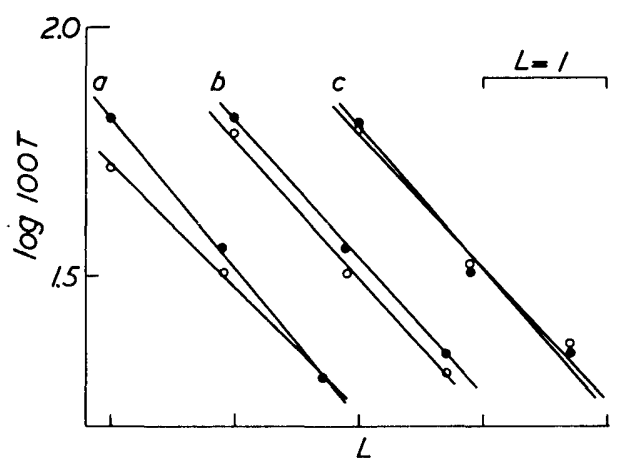

Fig. 5-4-Transmission $\mathrm{T}$ of solar radiation in kale, plotted logarithmically as a function of the cumulative leaf area index $\mathrm{L}$ with arbitrary origin.

\begin{tabular}{|c|c|c|c|c|}
\hline Curve & \multirow{2}{*}{ GMT } & \multirow{2}{*}{$\beta^{\mathrm{o}}$} & \multicolumn{2}{|c|}{$\mathrm{s}$} \\
\hline & & & Overcast & Clear \\
\hline a & $08-10$ & $28-43$ & 0.33 & 0.41 \\
\hline b & $10-14$ & $43-50$ & 0.37 & 0.37 \\
\hline c & $14-16$ & $28-43$ & 0.35 & 0.40 \\
\hline
\end{tabular}




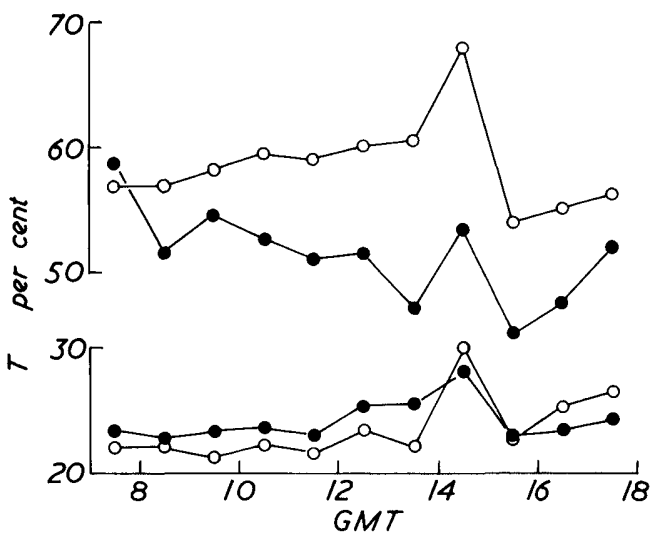

Fig. 5-5-Transmission of solar radiation (open circles) and of net radiation (full circles) in a stand of barley, measured at heights of $45 \mathrm{~cm}$ (upper lines) and $10 \mathrm{~cm}$ (lower lines).

The difference observed at $45 \mathrm{~cm}$ may be a real effect of temperature gradients in the upper part of the foliage or may be the result of small differences in the distribution of leaf area with height over the ground where the two sets of instruments were exposed. Figure 5-6 shows the diurnal change of $s$ in a mature stand of barley at Rothamsted, justifying the assumption that $s$ is constant within \pm 4 hours of noon (corresponding to $30<\beta<60^{\circ}$ at the time of measurement.)

Pearce, Brown, and Blaser (1968) reported an ingenious experiment in which barley was grown in trays inclined to the horizontal so that the seedlings grew vertically at an angle to the soil surface. The

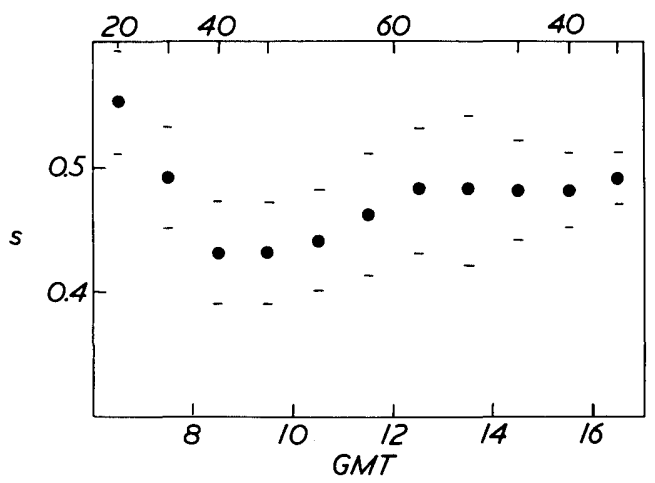

Fig. 5-6-Diurnal variation of $\mathrm{s}$ in a stand of barley growing to $53 \mathrm{~cm}$ height on 23 June 1963. The standard deviations were calculated from the fit of the relation

$$
\ln \mathrm{T}=\mathrm{L}\{\mathrm{s}+(1-\mathrm{s}) \tau\}
$$

to measurements at three values of $\mathrm{L}$. 
trays were then placed horizontally under an extended light source and the transmission was measured with a selenium photocell. The mean angles of leaves to the horizontal were 90,53 , and $18^{\circ}$ and corresponding mean values of $\mathrm{KV}$ were $0.32,0.42$, and 0.64 . Corresponding differences of photosynthesis rate agreed well with predictions from the theory of Monsi and Saeki (1953).

\section{Beans}

Measurements with tube solarimeters at Rothamsted confirmed that the diurnal variation of $s$ was negligible. As the canopy expanded to a leaf area index of $\mathrm{L}=4$, the logarithm of the daily mean light transmission decreased linearly with increasing L (Fig. 5-7). This result implies that the geometry of the foliage was invariant with age. Figure 5-7 also shows the attenuation of infrared radiation, giving the same value of $s=0.53$ as the attenuation of total radiation.

\section{Rice}

Hayashi and Ito (1962) found a wide variation of $\mathrm{KV}$ in varieties of rice with different leaf geometry. In general, the more erectophile varieties developed larger leaf area indices and produced more dry matter at a given leaf area.

\section{Ryegrass}

Brougham (1958) found that the diurnal change of transmission was even more pronounced in ryegrass than in clover. Kuriowa and Monsi (1963) fitted Brougham's data to a theoretical curve for foliage at a fixed angle $\alpha=80^{\circ}$. This value is unrealistically large even for erectophile foliage and the theoretical comparison therefore casts further doubts on the validity of the original measurements.

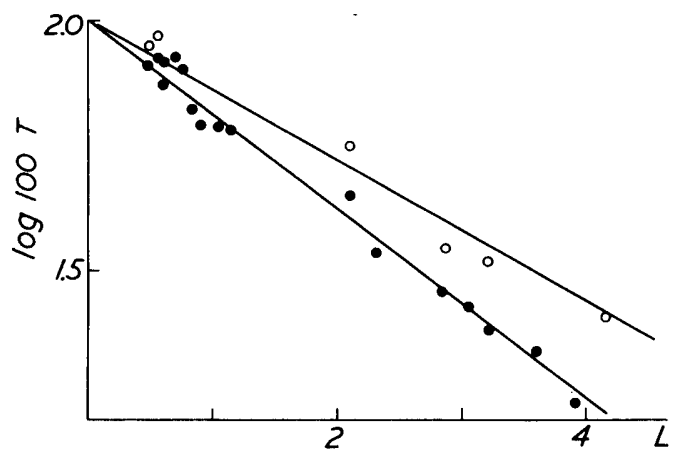

Fig. 5-7-Transmission of solar radiation (full circles) and infrared radiation (open circles) in a stand of beans (Vicia faba) as a function of the leaf area index. Each point represents the average transmission on a day between 25 May and 20 June, 1966. 


\section{CONCLUSIONS}

1) Several models of light distribution in crops are based on an assumption that the arrangement of foliage is effectively random. In real crops, the spacing of leaves cannot be random because it is determined by the pattern of sowing and by phyllotaxy. A critical study of radiation in relation to leaf geometry is needed to establish whether random or very regular models of canopy structure give the truest description of light distribution and hence the best estimates of photosynthesis.

2) Purists have argued that because the fraction of radiation intercepted by a leaf layer depends in principle on the incident angle of radiation, the diurnal variation of $K$ (or $s$ ) must be taken into account in models of light distribution and photosynthesis. Direct measurements of radiation in crops with a wide range of leaf sizes and angles support the opposite view: that the variation of $\mathrm{K}$ is usually small enough to neglect, at least over the central 8 hours of the day when most assimilation takes place. This result is consistent with theory provided there is a preponderance of leaf angles less than $30^{\circ}$.

3) Models of photosynthesis reveal that for leaf indices usually met in the field, say 4 to 8 in mature stands, photosynthesis rates are not strongly dependent on leaf angle. At large leaf areas, however, say from 8 to 12 , theory predicts that erectophile stands should make more efficient use of light than planophile stands. Critical field experiments are needed to test these predictions as the existing evidence is scanty and inconclusive. In terms of yield at harvest, as distinct from instantaneous rates of photosynthesis, differences of leaf angle are likely to be much less significant than differences in the rate at which the canopy expands to form a complete cover or differences in the rate of respiration per unit leaf area.

4) Progress depends on combining measurements of radiation, properly averaged in time and in space, with corresponding measurements of leaf area distribution determined from an adequate number of samples. In practice, this combination is rare and many studies of light distribution in crops suffer from a disparity in the precision of physical and biological measurements.

5) There is a danger of crop ecologists becoming preoccupied with models at the expense of measurements. This emphasis is irrational because one of the main functions of models is to integrate knowledge

derived from measurements in order to predict the response of crops to their environment. Models simulate; but measurements summarize information.

\section{ACKNOWLEDGEMENTS}

Several workers kindly provided unpublished measurements for incorporation in Table 5-2. I am grateful to Dr. J. Warren Wilson for discussion of some of the issues raised in this paper and to Dr. J.R. 
Philip whose response to a preliminary draft provided a stimulating basis for public and private debate in Lincoln.

\section{LITERATURE CITED}

Alberda, T. L. 1966. Responses of grasses to temperature and light. In The growth of cereals and grasses. Ed. Milthorpe and Ivins. Butterworths, London.

Allen, L. H., and K.W. Brown. 1965. Shortwave radiation in a corn crop. Agron. J.57:575-580.

Allen, L. H., C. S. Yocum, and E. R. Lemon. 1964. Photosynthesis under field conditions: VII. Radiant energy exchange. Agron. J. 56:253-259.

Anderson, M. C. 1964. Light relations of terrestrial plant communities. Biol. Rev. $39: 425-486$.

Anderson, M. C. 1966. Stand structure and light penetration II. J. Appl. Ecol. $3: 41-54$.

Avaste, O., H. Moldau, and K. S. Shifrin. 1962. Spectral distribution of direct and diffuse radiation. Akad. Nauk. Est. SSR. Inst. Phys. Astron. no. 3.

Baker,D. N., and R.E. Meyer. 1966. Influence of stand geometry on light interception and net photosynthesis in cotton. Crop Sci. 6:15-19.

Begg, J. E., J. F. Bierhuizen, E. R. Lemon, D. K. Misra, R. O. Slatyer, and W. R. Stern. 1964. Diurnal energy and water exchanges in bulrush millet. Agr. Meteorol. 1:294-312.

Brougham, R. W. 1958. Interception of light by the foliage of pure and mixed stands of pasture plants. Aust. J. Agr. Res. 9:35-52.

Cowan, I. R. 1968. The interception and absorption of radiation in plant stands. J. Appl. Ecol. 5:367-379.

Denmead, O. T., L. J. Fritschen, and R. H. Shaw. 1962. Spatial distribution of net radiation in a corn field. Agron. J. 54:505-510.

Dogniaux, R. 1954. Etude du climat de la radiation in Belgique. Inst. Roy. Meteorol. Belgique Contrib. No. 18.

Donald, C. M. 1961. Competition for light in crops and pastures. Symp. Soc. Exp. Biol. XV. 282-313.

Duncan, W. G., R. S. Loomis, W. A. Williams, and R. Hanau. 1967. A model for simulating photosynthesis in plant communities. Hilgardia 38(No. 4):181-205.

Duncan, W. G., W. A. Williams, and R. S. Loomis. 1967. Tassels and the productivity of maize. Crop Sci. 7:37-39.

Evans, G. C., and D. E. Coombe. 1959. Hemispherical and woodland canopy photography. J. Ecol. 47:103-113.

Friend, D. T. C. 1961. A simple method of measuring integrated light values in the field. Ecol. 42:577-580.

Gaastra, P. 1968. Radiation measurements for investigations of photosynthesis under natural conditions. In Eckardt (ed.). Functioning of terrestrial ecosystems. UNESCO, Paris.

Gates, D. M., H. N. Keegan, J. C. Schleter, and V. R. Weidner. 1965. Spectral properties of plants. Appl. Optics 4:11-20.

Green,D. A., L. H. Jones, and N. J. T. Melican. 1967. Radiation measurements. In The measurement of environmental factors in terrestrial ecology. British Ecological Society Symposium no. 8:257.

Hayashi, K., and H. Ito. 1962. Studies on the form of plant in rice varieties. Crop Sci. Soc. Japan 37:329-333.

Hiroi, T., and M. Monsi. 1966. Dry matter economy of Helianthus annuus communities. J. Faculty Sci., Tokyo III, 9:241-285.

Horie, T. 1966. Preliminary report of a method for estimating sunlit leaf area within a corn canopy. J. Agr. Meteorol. Tokyo 22:125. 
Isobe, S. 1962. Preliminary studies on physical properties of plant communities. Bull. Nat. Inst. Agr. Sci. A. no. 9, 29-66.

Jones, L. H. 1969. Proceedings of VIIth Eucarpia Congress (In the press)

Kasanaga, H., and M. Monsi. 1954. On the light transmission of leaves. Jap. J. Bot. 14:304-324.

Kriedeman, P. E., T. F. Neales, and D. H. Ashton. 1964. Photosynthesis in relation to leaf orientation and light interception. Aust. J. Biol. Sci. 17:591-600.

Kuriowa, S. 1968. A new calculation method for photosynthesis of a plant community. In Functioning of terrestrial ecosystems. Proc. Copenhagen Symposium UNESCO, Paris.

Kuriowa, S., and M. Monsi. 1963. Theoretical analysis of light factor and photosynthe sis in plant communities. J. Agr. Meteorol. 18:143-151.

Loomis, R. S., W. A. Williams, and W. G. Duncan. 1967. Community architecture and the productivity of terrestrial plant communities, p. 291-308. In A. San Pietro, F. A. Greer, and T. J. Army (ed.) Harvesting the sun. Academic Press, New York.

Loomis, R. S., W. A. Williams, W. G. Duncan, A. Dovrat, and F. Nunez. 1968. Quantitative descriptions of foliage display and light absorption of corn plants. Crop Sci. 8:352-356.

Ludwig, L. C., T. Saeki, and L. T. Evans. 1965. Photosynthesis in artificial communities of cotton plants. Aust. J. Biol. Sci. 18:1103-1118.

McCree, K. J. 1968. Infrared sensitive film for spectral measurements under plant canopies. Agr. Meteorol. 5:203-208.

Miller, E. E. 1951. Averaged measurement of optical transmission. Rev. Sci. Inst. $22: 56-57$.

Monsi, M., and T. Saeki. 1953. Uber den Lichtfaktor in den Pflanzengesellschaften. Jap. J. Bot. 14:22-52.

Monteith, J. L. 1965. Light distribution and photosynthesis in field crops. Ann. Bot. $29: 17-37$.

Moss, D. N. 1964. Optimum lighting of leaves. Crop Sci. 4:131-136.

Pearce, R. B., R. H. Brown, and R. E. Blaser. 1965. Relationships between leaf area index, light interception and net photosynthesis in orchardgrass. Crop Sci. 5:553-556.

Pearce, R. B., R. H. Brown, and R. E. Blaser. 1967. Photosynthesis in plant communities as influenced by leaf angle. Crop Sci. 7:321-324.

Philip, J. R. 1965a. The use of point-quadrats with special reference to stemlike organs. Aust. J. Bot. 14:105-125.

Philip, J. R. 1965b. The distribution of foliage density with foliage angle estimated from inclined point-quadrat observations. Aust. J. Bot. 13:357-366.

Reeve, J. E. 1960. Appendix on derivation of formulae (In Inclined point quadrats, J. Warren Wilson) New Phytol. 59:1-8.

Reifsnyder, W. E., and H. W. Lull. 1965. Radiant energy in relation to forests. USDA Tech. Bull. no. 1344.

Roach, S. A. 1968. The theory of random clumping. Methuen, London.

Robinson, N. 1966. Solar radiation. Elsevier, Amsterdam.

Ross, Yu. K., and T. Nilson. 1967a. Biometric characteristics of a maize stand. In Nichiporovich (ed.) Photosynthesis of productive systems. Israel Program of Scientific Transl., Jerusalem.

Ross, Yu. K. and T. Nilson. 1967b. The spatial orientation of leaves in crop stands. In Nichiporovich (ed.) Photosynthesis of productive systems. Israel Program of Scientific Transl., Jerusalem.

Saeki, T. 1963. Light relations in plant communities. In L. T. Evans (ed.) Enenvironmental control of plant growth. Academic Press, New York.

Saito, T. 1964. Method of measurement of transmissivity of atmospheric radiation and of calculation of net longwave radiation within plant communities. J. Agr. Meteorol. Tokyo. 20:7-10.

Sakomoto, C. M., and R. H. Shaw. 1967. Light distribution in field soyabean canopies. Agron. J. 59:7-9. 
Singh, M., D. B. Peters, and J. W. Pendleton. 1968. Net and solar radiation in soybean canopies. Agron. J. 60:542-545.

Stern, W. R., and C. M. Donald. 1962. Light relationships in grass-clover swards. Aust. J. Agr. Res. 13:599-614.

Szeicz, G. 1965. A miniature tube solarimeter. J. Appl. Ecol. 2:145-147.

Szeicz, G. 1966. Field measurements of energy in the $0.4-0.7$ micron range. In Light as an ecological factor. British Ecol. Soc. Symp. 6.

Szeicz, G., J. L. Monteith, and J. M. Dos Santos. 1964. Tube solarimeter to measure radiation among plants. J. Appl. Ecol. 1:169-174.

Tageeva, S. V., and A. B. Brandt. 1961. Optical properties of leaves depending on the angle of light incidence. In B. C. Christenson et al. (ed.) Progress in photobiology. Elsevier, Amsterdam.

Tanner, C. B., A. E. Peterson, and J. R. Love. 1960. Radiant energy exchange in a corn field. Agron. J. 52:373-379.

Tooming, Kh. 1967. An approximate method for determining the attenuation and reflection of PHAR. In Nichiporovich (ed.) Photosynthesis of productive systems. Israel Program of Scientific Transl. Jerusalem.

Tooming, Kh., and Yu. K. Ross. 1964. Radiatsionnyi rezhim poseva kukuruzy po yarusam. Iss. Fiz. Atmas. 6.

Warren Wilson, J. 1965. Stand structure and light penetration I. J. Appl. Ecol. $2: 383-390$.

Warren Wilson, J. 1960. Inclined point quadrats. New Phytol. 59:1-8.

Warren Wilson, J. 1963. Estimation of foliage density and foliage angle by inclined point quadrats. Aust. J. Bot. 11:95-105.

Warren Wilson, J. 1967. Stand structure and light penetration III. J. Appl. Ecol. 4:159-165.

Wilfong, R. T., R. H. Brown, and R. E. Blaser. 1967. Relationships between leaf area index and apparent photosynthesis in Alfalfa and Ladino Clover. Crop Sci. 7:27-30.

Williams, W. A., R. S. Loomis, and C. R. Lepley. 1965. Vegetative growth of corn. Crop Sci. 5:211-215.

deWit, C. T. 1965. Photosynthesis of leaf canopies. Agr. Res. Reports 663, I.B.S. Wageningen.

\title{
5...DISCUSSION
}

\author{
K. L. MCCREE
}

Texas A \& M University

College Station, Texas

I believe we could usefully spend a few minutes defining terms. In this field, it has become customary to use the words "light intensity" for the flux received per unit area. Unfortunately, this leaves us without a term for the more fundamental variable in any light calculation, the flux emanating from the source (or sources). This is what the photometrist calls the intensity. The radiant flux density at a surface is 
properly called the irradiance, and in the international system of units (S.I.) it is measured in $\mathrm{W} / \mathrm{m}^{2}$. The luminous flux density is called the illumination, and it is measured in lux (lumens $/ \mathrm{m}^{2}$ ) or in footcandles (lumens/ $\mathrm{ft}^{2}$ ). The International Lighting Vocabulary (C.I.E., 1957), the USA Standard of Nomenclature (USA Standards Institute, 1967), and the I.E.S. Lighting Handbook (Kaufman, 1966) should be consulted for further information on terms, definitions and techniques used in the general field of light measurement.

I have some comments on the proportion of photosynthetically active radiation in natural daylight. According to measurements in New Zealand (McCree, 1966) and in the Netherlands (Gaastra, 1968), in lessthan perfect climates the proportion can vary over the range 38 to $65 \%$. Moreover, the variation is systematic, the highest percentages occurring at the lowest irradiances, presumably because of the absorption of the infrared fraction by the water vapor in clouds. Since the leaves of plants are nonlinear integrators, the error resulting from the use of the single figure of $50 \%$ may not always be negligible.

I support your plea for more experimental testing of models, but I think we should be quite clear about which models, or parts of models, we are testing. I do not believe that one can "test models of light penetration by comparing predicted rates of dry matter accumulation with measurements in the field." The manner of light penetration is only one of a very large number of parameters which should go into a model of dry matter accumulation, and it is naive to ascribe differences observed in field experiments to any one parameter. Assumptions made about the dependence of light penetration on the geometry of the crop and of the incident light, in models of dry matter accumulation (or grain harvest, or water use, or any other plant response), should be tested by measuring the geometry and thelight penetration.

For this purpose, it could be legitimate to average the irradiance measurements in time and space, but this is not what the plant does (McCree, 1965). It integrates $\mathrm{CO}_{z}$ molecules, not quanta, and any respectable model of crop photosynthesis should do the same. For such a model, the pertinent information on light penetration is not the average irradiance but the area of leaf which is exposed to a given irradiance at a given instant, but this is scarcely amenable to measurement in the field. Hence the need for theories of light penetration.

Are plants perfect time integrators of $\mathrm{CO}_{2}$ molecules? The results of some experiments made in Davis indicate that they are (McCree and Loomis, 1969). In these experiments, cucumber plants (Cucumis sativa L.) were presented with light which alternated between two levels of irradiance, within the range 16 to $220 \mathrm{~W} / \mathrm{m}^{2}$ (simulating sunlight and skylight), the bright and dull periods being equal in length, within the range $10^{-2}$ to $10^{3}$ sec. The mean photosynthetic rate in fluctuating light was within a few percent of the mean of the two photosynthetic rates, obtained in steady light at the two levels of irradiance which were alternated. Deviations of up to $20 \%$ were obtained when a high irradiance was alternated with complete darkness, an unnatural condition similar to those used in early experiments on flashing light. 


\title{
LITERATURE CITED
}

C.I.E. (Commission Internationale de 1.Eclairage). 1957. International lighting vocabulary, 2nd ed. (3rd ed. is in press). Vol.1. Bureau Central de la C.I.E., 57 Rue Cuvier, Paris 5, France. (obtainable in the USA from the Secretary, U.S. National Committee for the C.I.E., National Bureau of Standards, Washington, D.C. 20234).

USA Standards Institute. 1967. USA Standard RP-16 (USAS Z7.1-1967): Nomenclature and definitions for illuminating engineering. (obtainable from the Illuminating Engineering Society. 345 East 47th Street, New York, N.Y. 10017).

Kaufman, John E. (ed.) 1966. I.E.S. Lighting handbook. 4th ed. Illuminating Engineering Society, 345 East 47th Street, New York, N.Y. 10017.

Gaastra, P. 1968. Radiation measurements for investigations of photosynthesis under natural conditions. In Eckardt (ed.). Functioning of terrestrial ecosystems at the primary production level. Proc. Copenhagen Symp., Paris, UNESCO.

McCree, K. J. 1966. A solarimeter for measuring photosynthetically active radiation. Agr. Meteorol. 3:353-366.

McCree, K. J., and R. S. Loomis. 1969. Photosynthesis in fluctuating light. Ecology: in press.

McCree, K. J. 1965. Light measurements in plant growth investigations. Nature $206: 527-528$, and 210:753 (1966).

\section{5... DISCUSSION}

\author{
JOHN R. PHILIP
}

CSIRO Division of Plant Industry

Canberra, Australia

\section{NONRANDOMNESS OF FOLIAGE DISTRIBUTION}

A proper analysis of nonrandomness in foliage distribution has not yet been developed, in my opinion. To take $n$ in Monteith's paper as infinite seems to overlook some important points:

1) The case $n=$ finite implies a very special form of nonrandom structure, involving exact and rigid geometrical constraints which do not apply to vegetation. It must be understood that the value $n=0$ does not forbid nonrandomness and seems appropriate to foliage.

2) Used as described in Monteith's paper, a finite n cannot represent underdispersion. 


\section{DISTRIBUTION OF RADIANT FLUX DENSITY ON FOLIAGE SURFACES}

Many authors have emphasized that it is not enough to know the mean irradiance received at foliage surfaces. Because of the usual nonlinearity of the photosynthetic response to radiation, we need to understand the distribution of irradiance. The remainder of this discussion considers certain influences on this distribution. Progress seems best served if we can assess the relative importance of various influences and concentrate our attention on the important ones. I discuss three influences: (i) foliage inclination to incident radiation; (ii) the finiteness of the sun's disc; and (iii) transmission through leaves. I shall treat all three with reference to direct radiation at the top of the canopy. Extensions (where relevant) to diffuse radiation will be obvious.

\section{FOLIAGE INCLINATION TO INCIDENT RADIATION}

The flux density of incident radiation increases from zero to its maximum as the angle of incidence increases from $0^{\circ}$ to $90^{\circ}$. In general all angles of incidence will occur and thus the full scale of densities will be received. This seems to be the major (though, of course, not the only) cause of the distribution of incident densities.

\section{FINITE RADIUS OF THE SOLAR DISC}

As Minnaert (1954) explains, "sun-pictures" occur because the sun's disc subtends a definite nonzero angle at the earth's surface, $\zeta$. $\zeta=0.093 \mathrm{rad}=0.53^{\circ}$. For the same reason shadows cast in direct sunlight are contained, not by a cylindrical surface with axis in the sun's direction, but by a tapering surface everywhere inclined at angle $\zeta / 2$ to this axis. (We use "shadow" in the sense of umbra, the region which receives no direct illumination.) With increasing distance from the object, shadows [on planes in any fixed orientation] get progressively smaller; all such shadows except circular ones become more elongated; and all shadows disappear at distance $\mathrm{d} /(2 \sin \zeta / 2)[\approx \mathrm{d} / \zeta]$, where $\mathrm{d}$ is the "minimum diameter" of the projection of the obstacle on a plane normal to the direction of the sun.

The fact of the finiteness of the sun's disc was recognized in passing by Warren Wilson (1967), but, so far as I know, it has been ignored to date in all calculations of distribution of irradiance in canopies.

A leaf presenting a minimum diameter of $1 \mathrm{~cm}$ casts no shadow beyond $107 \mathrm{~cm}$; and a sunlit hole of $0.1 \mathrm{~cm}$ diameter illuminates 100 times its area [at roughly 1/100 intensity] at a level $100 \mathrm{~cm}$ below it. Figures such as these point up the fact that the finiteness of the sun's disc should be taken into account in investigations of the radiation climate in tall vegetation. Studies of plant structure concerned with optimum morphology for photosynthesis should not ignore it either. 


\section{TRANSMISSION THROUGH LEAVES}

Direct radiation, of density $\mathrm{I}_{0}$ on a plane normal to ray, arrives at top of canopy. Direct radiation incident on foliage is supposed to be absorbed, except for a fraction $\tau$ transmitted from lower surfaces as diffuse radiation, $D$. If $\overline{\mathrm{I}}$ is mean direct irradiance

$$
\frac{d \bar{I}}{d \ell}=-\bar{I} \text { so that } \bar{I}=I_{O} \exp (-\ell)
$$

where $\ell$ is cumulative LAI projected on plane normal to ray.

Also

$$
\frac{\mathrm{dD}}{\mathrm{d} \ell}=-(1-\tau) \mathrm{D}-\tau \frac{\mathrm{d} \overline{\mathrm{I}}}{\mathrm{d} \ell},
$$

where, for simplicity, we treat the absorption and transmission of diffuse radiation as similar to that of direct. Combining (1) and (2) and solving, we get

$$
\mathrm{D}=\mathrm{I}_{\mathrm{O}}[\exp [-(1-\tau) \ell]-\exp (-\ell)]
$$

Whence at position $\ell$, the distribution of irradiances (on planes normal to direct radiation) is as follows:

Over "sunlit area" $\exp (-\ell)$,

$$
\text { irradiance }=\mathrm{I}_{\mathrm{O}}+\mathrm{D}=\mathrm{I}_{\mathrm{O}}\{1+\exp [-(1-\tau) \ell]-\exp (-\ell)\} \text {. }
$$

Over "shaded area" $1-\exp (-\ell)$,

$$
\text { irradiance }=D=I_{O}\{\exp [-(1-\tau) \ell]-\exp (-\ell)\} .
$$

$\tau=0.07$ for wavelengths of interest. $D$ has maximum value approx. $0.027 \mathrm{I}_{\mathrm{O}}$ at $\ell=$ approx. 1 .

This analysis avoids difficulties of Monteith (1965) of (i) taking $n=$ finite, and (ii) treating transmitted light as direct, which it is not. Note that $\mathrm{D} / \mathrm{I}_{\mathrm{O}}$ is usually trivially small.

\section{ADDITIONAL LITERATURE REFERENCE}

Minnaert, M. 1954. The nature of light and color in the open air. Dover, New York. 